\title{
Properties of Reactive Powder Concrete Using Local Materials and Various Curing Conditions
}

\author{
Gamal I. K, K. M. Elsayed, M. H. Makhlouf and M. Alaa
}

\begin{abstract}
Reactive Powder Concrete RPC is comprised of (cement, quartz powder, sand, and superplasticizer) mixture with low water/cement ratio. It has not coarse aggregates and characterized by highly dense matrix, high strength concrete, excellent durability, and economic. This study aims to investigate fresh and hardened properties of locally cast RPC with several available economical materials such as silica fume (SF), fly ash (FA), steel fiber (STF), and glass fiber (GF). Experimental investigation was performed to study the effectiveness of partial replacement of cement by SF or FA to reach ultra-high strength concrete, effect of additional materials STF or GF in order to improve the fracture properties of the RPC mixes, and influence of the treated with normal water as well as with hot water. Fifteen different RPC mixes were cast with $20,25,30$, and $35 \%$ cement replacement by SF, $25 \%$ cement replacement by FA, and another proportions taken combination between SF and FA with percentages 15, 20, 25\% FA and constant $10 \%$ SF. Varying fiber types (steel fiber or glass fiber) added to concrete by different percentages 1,2 , and $3 \%$. Specimens were treated with normal water $25^{\circ} \mathrm{C}$ and hot water at $60^{\circ} \mathrm{C}$ and $90^{\circ} \mathrm{C}$ by 2 mixes with silica fume content $25 \%$ of binder and steel fiber content $2 \%$ by total volume. Performance of the various mixes is tested by the slump flow, compressive strength, flexure strength, splitting tensile strength, and density. The production of RPC using local materials is successfully get compressive strength of $121 \mathrm{MPa}$ at the age of 28 days at standard conditions and normal water curing $25^{\circ} \mathrm{C}$ with Silica fume content $25 \%$ of binder and steel fiber content $2 \%$ by total volume of RPC and water/binder ratio of 0.25 . The results also showed the effect of curing by hot water 60 and $90^{\circ} \mathrm{C}$, it is observed that compressive strength increases proportionally with curing temperatures and a compressive strength of 149.1 $\mathrm{MPa}$ at $90^{\circ} \mathrm{C}$ for 1 days was obtained.
\end{abstract}

Index Terms — Reactive Powder Concrete, Silica Fume, Fly Ash, Steel Fiber, Glass Fiber.

\section{INTRODUCTION}

Concrete is a very used construction material and has undergone many researches and development over the last decade. Concrete has now grown into a material that can be used in any environment exposed to it. New and exciting progress has been made since its inception.

Published on June 18, 2019.

Gamal I. K, professor of Reinforced concrete, Department of Civil Engineering, Benha Faculty of Engineering, Benha University, Egypt (email: gamal.ismail@ bhit.bu.edu.eg).

K. M. Elsayed, Associate Prof. in the Department of Civil Engineering, Benha Faculty of Engineering, Benha University, Egypt (e-mail: khelsayed@ hotmail.com).

M. H. Makhlouf, Assistant Prof. in the Department of Civil Engineering, Benha Faculty of Engineering, Benha University, Egypt (e-mail: mohamedmakhlouf83@yahoo.com).

M. Alaa, Demonstrator at Higher Institute of Engineering and Technology in Obour, Egypt (e-mail: engmalaa1507@gmail.com).
Reactive Powder Concrete-RPC is a comparatively new cementitous material. It's composed of high cement content, low water/cement ratio, very fine quartz powder, and sand. Coarse aggregate used in normal concrete is completely replaced by fine quartz sand and crushed quartz. High Performance Concrete (HPC) may provide an ultimate compressive strength of 50 to $100 \mathrm{MPa}$ [1], but RPC is characterized very high performance in mechanical properties, particularly in compressive strength, which can be in the range of 150 to $800 \mathrm{MPa}$. RPC was discovered by the scientific division of Bouygues in the early of 1990s, it is a new generation cement based composite developed by microstructural enhancement techniques. The term "reactive powder" reflects the fact that all components of the powder in RPC react chemically to the following casting cement by traditional moisturizing; silica dust through the pozzolanic reaction with the resulting calcium hydroxide. Quartz by providing silica melted to form more calcium silicate gel C$\mathrm{S}-\mathrm{H}$ hydrates; quartz powder to change the ratio of $\mathrm{CaO} /$ $\mathrm{SiO} 2$ and preferably tobermorite and xonolite formation when RPC is exposed to heat treatment or pressure adjustment [2]. Previous research shows that the mechanical properties of the RPC increase in tensile strength and ductility about 250 times greater than the normal strength concrete [3]. RPC is known as a concrete that can provide a combination of ultra-high strength and high ductility by including short reinforcement of steel fibers [4]. The RPC configuration is free of empty aggregates and is different from normal concrete. Fine powders used such as quartz sand and crushed quartz, with sizes ranging from 45: 600 micrometers. In fact, RPC is a mortar of an original concrete mixture because there is no coarse aggregate and can provide a compressive strength to $130 \mathrm{MPa}$ [5]. Many successful applications of RPC such as the $60 \mathrm{~m}$ span Sherbrook Bridge in Canada; the 25-meter span Future Bridge in USA, used for sea walls anchors in Portugal, used for vehicular bridges in Australia, and has been used in the production of structural beam components, manhole covers, road accessories and others.

Many researchers have conducted RPC studies over the past years to assess the characteristics and behavior of the reactive concrete [6-14]. Chan and chu. [6] studied the effect of using silica fume (SF) on the characteristics of bonding of steel fibers in a matrix of reactive powder concrete (RPC) through bond strength and pull energy, where silica fume contents range from $0 \%$ to $40 \%$ used in mixing ratios, their findings show that the incorporation of the silica fume membrane can effectively enhance the fiber-matrix interface properties, particularly in the fiber-pulling capacity. Shaheen and Shrive [7] coincidentally achieved Light Reactive Powder Concrete (LRPC) with density of as low as 
$1760 \mathrm{~kg} / \mathrm{m} 3$ having high compressive strength values in their study by replacing carbon fiber with some amount of aggregates, in the manufacture of RPC using the lightweight aggregate is not preferred. Strong quartz aggregates are usually used in order to reach high strength grade. Sadrekarimi [8] produced the LRPC by means of high amount of silica fume replacement. In his study, high silica fume content increases the compressive strength; however, it decreases the density as low as $1900 \mathrm{~kg} / \mathrm{m}^{3}$. Zhang et al. [9] they investigated mechanical characteristic of RPC by utilizing composite mineral admixtures, and steel fibers with different mixture ratios, the experimental results show that the properties of RPC made with the cementitious materials consisting of cement, fine slag, fine fly ash, silica fume with ratios $(40,25,25$, and 10$) \%$ respectively , and $4 \%$ volume fraction of steel fiber are higher efficiency than the others mixes, were give compressive strength, flexural strength, and bonding strength are more than 200 $\mathrm{MPa}, 60 \mathrm{MPa}$, and $14 \mathrm{MPa}$, respectively. H. M. Al-Hassani et al. [10] investigated the mechanical properties of RPC. These characteristics included compressive strength, modulus of elasticity, tensile strength, and flexural strength. The main parameters in the research where used the silica fume content (SF) as a partial replacement of cement, steel fiber volume fraction and different types of superplasticizer. The effect of these variables on the properties of RPC were studied. The experimental results showed the increase in (SF) content from $0 \%$ to $30 \%$ lead to a significant increase in compressive strength, while the increase in tensile strength is relatively lower. The implying of steel fibers leads to a large increase in tensile strength but a slight increase in compressive strength.

O. Elouh et al [11] the using of RPC carried out compressive strength of $165.40 \mathrm{MPa}$ at the age of 28 days at normal water curing temperature $25^{\circ} \mathrm{C}$ is achieved. Also compressive strength of $191.15 \mathrm{MPa}$ at the age of 28 days at curing at $90^{\circ} \mathrm{C}$ for 3 days is obtained. RPC is suitable for pre-casting concrete and can achieve compressive strength value exceeding 191.15 $\mathrm{MPa}$ at heat curing when concrete produced with cement, W/C of 0.28 , steel fibers $3 \%$ (by total volume), quartz sand, crushed quartz powder, and silica fume $30 \%$ (by the weight of cement) as the mineral admixture $2.0 \%$ super-plasticizer (by the weight of cement). Mohammed Mansour et al. [12] were studies on the performance of RPC under two various curing conditions, normal curing at $25^{\circ} \mathrm{C}$ and heat treatment at $90^{\circ} \mathrm{C}$ and $95 \%$ relative humidity. Also, they studied the effect of using steel fiber and heat treatment on RPC slabs. Slabs specimens simply supported along four edges were loaded concentrically by a steel plate of dimension 70x70x25 mm. It was found that the use of steel fibers with heat treatment showed adequate improvement on the values of compressive strength, tensile strength, modulus of elasticity and flexural strength. Also, the experimental results showed that the presence of fine steel fibers gives improved stiffness, reduced crack width and propagation of cracks.

Inorganic additives are added to concrete in greater quantities to enhance the workability of fresh concrete; to improve the resistance of concrete to thermal cracking, alkali expansion and sulfur attack and to enable a reduction in cement content [13]. Griffiths et al. [14] carried out study to investigate the mechanical properties of concrete with glass fiber. The author observed that the addition of glass fibers to the concrete increases the modulus of rupture by about $20 \%$ and the fracture toughness by about $55 \%$. Glass fibers improve the strength of the concrete by increasing the force required for deformation and improve the toughness by increasing the energy required for crack propagation.

This study elucidates the impact of partial replacement of cement by silica fume, fly ash, and combination between them to reach ultra-high strength concrete, influence of the percentage variation of steel fiber and glass fiber in RPC mixes, and the effect of the curing condition with normal water and hot water on the mechanical properties of RPC

\section{MAterial Properties}

In this research, the materials used in the production of locally RPC mixes which were cement, silica fume, fly ash, quartz sand, crushed quartz, steel fiber, glass fiber, superplastisizers and water.

\section{A. Cement}

Cement used in this research was ordinary Portland cement CEM I - 42.5N, the physical properties of cement represented in table $\mathrm{I}$.

\begin{tabular}{ll}
\multicolumn{2}{c}{ TABLE I: PROPERTIES OF CEMENT } \\
\hline \hline Specific Gravity & 3.15 \\
Standard Consistency & $352 \%$ \\
Initial setting time (min.) & 75 \\
Final setting time (min.) & 380 \\
\hline \hline
\end{tabular}

\section{B. Silica fume:}

Silica fume used in this research from Sika Company in Egypt. Silica fume is a concrete additive of a new generation in powder form. Technical data of Silica Fume are given in table II.

TABLE II. PHYSICAL PROPERTIES OF SILICA FUME

\begin{tabular}{lc}
\hline Composition & A latently hydraulic blend of active ingredients \\
\hline Colour & Grey Powder \\
Specific gravity & 2.13 \\
Bulk Density & $300 \mathrm{~kg} / \mathrm{m} 3$ \\
\hline \hline
\end{tabular}

\section{Fly ash}

Fly ash used in this research from Sika Company in Egypt. Fly ash is a concrete additive of a new generation in powder form and spherical particles, which reduced the water requirements and makes a concrete is more cohesive and is less prone to segregation. Properties of fly ash are given in table III.

TABLE III PROPERTIES OF FLY ASH

\begin{tabular}{|c|c|}
\hline Composition & Alumina Silicate \\
\hline Colour & Grey-fine powder \\
\hline Specific gravity & 2.2 \\
\hline Bulk Density & $320 \mathrm{~kg} / \mathrm{m} 3$ \\
\hline
\end{tabular}

\section{Water}

Drinking water was used in experimental work for both 
concrete mixtures and in the treatment of samples.

\section{E. Superplasticizer}

In the study Visco Crete -1000 RM have been used from Sika Company in Egypt. Visco Crete $-1000 \mathrm{RM}$ is a superplasticizer for self-compacting concrete and mortar. Properties of superplasticizer are given in table IV.

\begin{tabular}{|c|c|}
\hline Aspect & Light brown liquid \\
\hline Relative Density & $1.12 \mathrm{~kg} / \mathrm{lt}$ \\
\hline $\mathrm{pH}$ & $\geq 6$ \\
\hline Chloride ion content & $<0.2 \%$ \\
\hline
\end{tabular}

\section{F. Quartz sand}

Quartz sand used in this research from Elhashem for minerals \& quartz materials Company in Egypt with a mean particle size of $10-15 \mu \mathrm{m}$ was employed. Properties of quartz sand are given in table $\mathrm{V}$.

TABLE V SAND CHEMICAL ANALYSIS

\begin{tabular}{ccc}
\hline \hline Oxides & $\%$ min. & $\%$ max. \\
\hline $\mathrm{SiO}_{2}$ & 99.4 & 99.6 \\
$\mathrm{Al}_{2} \mathrm{O}_{3}$ & 0.06 & 0.09 \\
$\mathrm{Na}_{2} \mathrm{O}$ & 0.05 & 0.07 \\
$\mathrm{~K} 2 \mathrm{O}$ & 0.01 & 0.02 \\
$\mathrm{CaO}$ & 0.02 & 0.09 \\
$\mathrm{MgO}$ & 0.03 & 0.03 \\
$\mathrm{Fe}_{2} \mathrm{O}_{3}$ & 0.012 & 0.018 \\
$\mathrm{TiO}_{2}$ & 0.017 & 0.021 \\
$\mathrm{Cr}_{2} \mathrm{O}_{3}$ & $2 \mathrm{ppm}$ & $2 \mathrm{ppm}$ \\
$\mathrm{L.O}_{2} .1$. & 0.15 & 0.25 \\
\hline \hline
\end{tabular}

\section{G. Crushed quartz powder}

RPC is produced using manufactured sand having particle size less than $2.36 \mathrm{~mm}$. Three different gradations are used, having size between 1.18 to $2.36 \mathrm{~mm}$ and specific gravity 2.65.

\section{H. Steel Fibers}

To improve the RPC ductility, mixes were produced with steel fibers of length $25 \mathrm{~mm}$ and diameter $0.8 \mathrm{~mm}$, with a tensile strength is $1000 \mathrm{MPa}$.

\section{Glass Fibers}

Glass Fibers used also to improve durability, increase impact resistance and reduced shrinkage cracks for RPC. In the study type $\mathrm{E}$ of glass have been used with properties extremely fine, single filaments, measuring 13 microns, length $18 \mathrm{~mm}$ and Specific Surface area equal $105 \mathrm{~kg} / \mathrm{m}^{2}$.

\section{MIX PROPORTION}

To perform the aims of this study, two groups of RPC with a total number of 15 mixtures were investigated as presented in table VI. The first group (G1-SF) with 950 $\mathrm{kg} / \mathrm{m} 3$ cementitious content is contains partial replacement SF only by $(20,25,30,35 \%)$ and steel fiber $2 \%$ or $25 \%$ SF and $(1,2,3 \%)$ steel fiber or $25 \% \mathrm{SF}$ and $(1,2,3 \%)$ glass fiber, which were treated with normal water $25^{\circ} \mathrm{C}$. Two mixes is contains partial replacement by $25 \%$ SF only and steel fiber $2 \%$ which were treated with hot water $60^{\circ} \mathrm{C}$, and $90^{\circ} \mathrm{C}$, that mixes from M01 to M11. While the second group (G2-FA) is contains $25 \%$ FA only and steel fiber $2 \%$, or combination from $10 \%$ SF and FA $(15,20,25 \%)$ with $2 \%$ steel fiber, as replacement materials by weight of cement (M12-M15).

\section{TEST PROCEDURE}

The consistency of RPC mixes is estimated flow test T500 and slump flow values of the fresh concrete tested. It is based on the flow test T500 test to measure two parameters, the flow speed and the flow time. The result is an indication of the workability of RPC. The compressive strength of RPC was tested using cubes $(70 \mathrm{~mm})$; this test was conducted at the ages of 7,14 , and 28 days. The splitting tensile strength test at 28 days age was carried out on cylindrical specimens of dimensions $(150 \times 70 \mathrm{~mm})$ was used for this test. The prism specimens of $60 \times 60 \times 400 \mathrm{~mm}$ for flexural strength test were used.

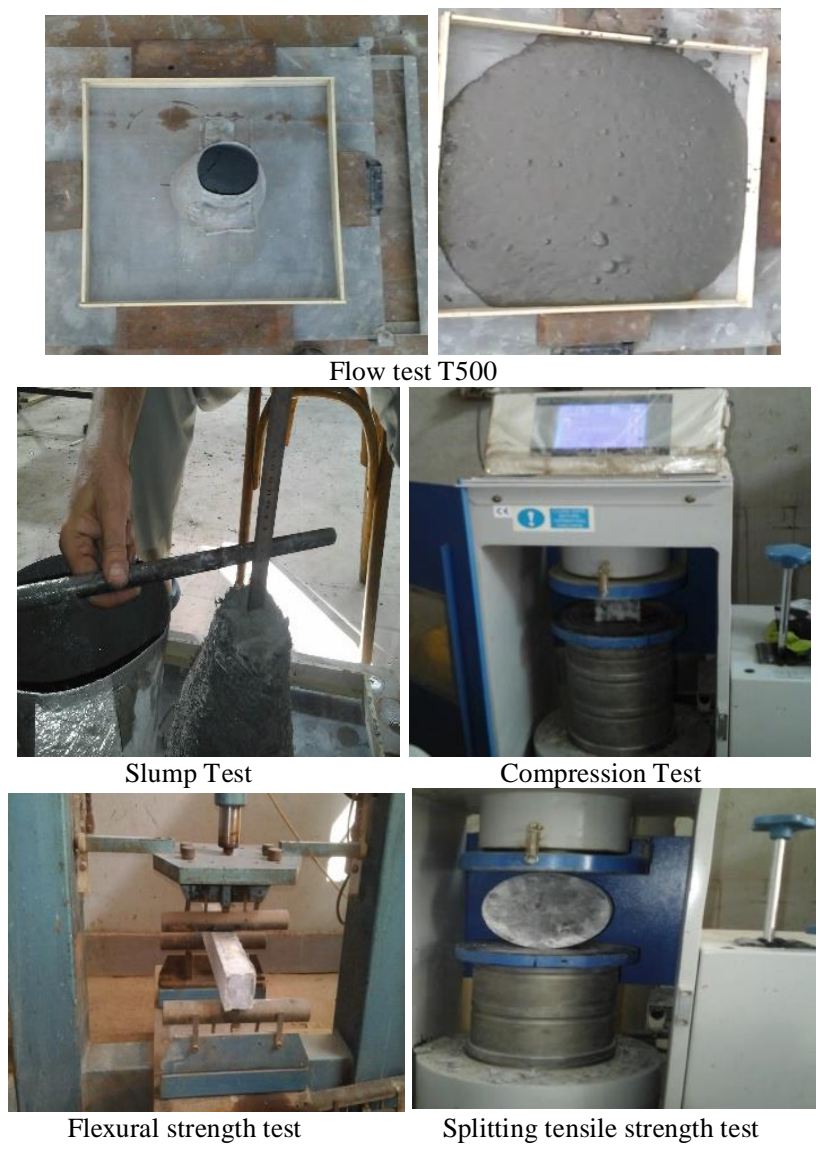

\section{Results AND Discussion}

The results of T500, slump, compressive strength, splitting tensile strength, and flexural strength are shown in table VII. The compressive strength of RPC mixes at various replacement of cement by (SF or FA, and combination between them) at 7, 14, and 28 days age are presented in table VII and Fig. 1.

Comparisons between the results of different mixes were carried out to reveal the effect of the parameters considered in this study. 
TABLE VI PROPORTIONS OF RPC MIXTURES

\begin{tabular}{|c|c|c|c|c|c|c|c|c|c|c|c|}
\hline Group & Mix No. & Cement kg/m³ & Quartz Sand kg/m3 & $\begin{array}{c}\text { Quartz powder } \\
\text { kg/m3 } \\
\end{array}$ & $\begin{array}{c}\text { SF } \\
\% \\
\end{array}$ & $\begin{array}{c}\text { FA } \\
\% \\
\end{array}$ & $\begin{array}{c}\text { STF } \\
\% \\
\end{array}$ & $\begin{array}{c}\text { GF } \\
\% \\
\end{array}$ & $\begin{array}{l}\text { SP } \\
\% \\
\end{array}$ & W/binder & $\begin{array}{c}\text { Curing temp. } \\
{ }^{\circ} \mathrm{C} \\
\end{array}$ \\
\hline \multirow{11}{*}{ G1-SF } & M01 & 700 & 875 & 215 & 20 & 0 & 2 & 0 & 2 & 0.25 & 25 \\
\hline & M02 & 650 & 875 & 215 & 25 & 0 & 1 & 0 & 2 & 0.25 & 25 \\
\hline & M03 & 650 & 875 & 215 & 25 & 0 & 2 & 0 & 2 & 0.25 & 25 \\
\hline & M04 & 650 & 875 & 215 & 25 & 0 & 3 & 0 & 2 & 0.25 & 25 \\
\hline & M05 & 600 & 875 & 215 & 30 & 0 & 2 & 0 & 2 & 0.25 & 25 \\
\hline & M06 & 550 & 875 & 215 & 35 & 0 & 2 & 0 & 2 & 0.25 & 25 \\
\hline & M07 & 650 & 875 & 215 & 25 & 0 & 2 & 0 & 2 & 0.25 & 60 \\
\hline & M08 & 650 & 875 & 215 & 25 & 0 & 2 & 0 & 2 & 0.25 & 90 \\
\hline & M09 & 650 & 875 & 215 & 25 & 0 & 0 & 1 & 2 & 0.25 & 25 \\
\hline & M10 & 650 & 875 & 215 & 25 & 0 & 0 & 2 & 2 & 0.25 & 25 \\
\hline & M11 & 650 & 875 & 215 & 25 & 0 & 0 & 3 & 2 & 0.25 & 25 \\
\hline \multirow{4}{*}{ G2-FA } & M12 & 650 & 875 & 215 & 0 & 25 & 2 & 0 & 2 & 0.25 & 25 \\
\hline & M13 & 650 & 875 & 215 & 10 & 15 & 2 & 0 & 2 & 0.25 & 25 \\
\hline & M14 & 600 & 875 & 215 & 10 & 20 & 2 & 0 & 2 & 0.25 & 25 \\
\hline & M15 & 550 & 875 & 215 & 10 & 25 & 2 & 0 & 2 & 0.25 & 25 \\
\hline
\end{tabular}

TABLE VII FRESH AND HARDENED PROPERTIES OF RPC MIXTURES

\begin{tabular}{|c|c|c|c|c|c|c|c|c|c|}
\hline \multirow{2}{*}{ Group } & \multirow{2}{*}{$\begin{array}{l}\text { Mix } \\
\text { No. }\end{array}$} & \multirow{2}{*}{$\begin{array}{l}\text { T500 Test } \\
\quad \text { (sec.) }\end{array}$} & \multirow{2}{*}{$\begin{array}{c}\text { Slump } \\
\text { Flow } \\
(\mathbf{m m})\end{array}$} & \multicolumn{3}{|c|}{$\begin{array}{c}\text { Compressive Strength } \\
(\mathrm{MPa}) \\
\end{array}$} & \multirow{2}{*}{$\begin{array}{l}\text { Splitting Tensile Strength } \\
\left(\mathbf{f}_{\mathrm{sp}}\right)(\mathrm{MPa})\end{array}$} & \multirow{2}{*}{$\begin{array}{c}\text { Flexural Strength }\left(\mathbf{f}_{\mathbf{r}}\right) \\
(\mathbf{M P a})\end{array}$} & \multirow{2}{*}{$\begin{array}{r}\text { Density } \\
\left(\mathrm{kg} / \mathrm{m}^{3}\right)\end{array}$} \\
\hline & & & & 7 day & $\begin{array}{c}14 \\
\text { day }\end{array}$ & $\begin{array}{c}28 \text { day } \\
\left(\mathbf{f}_{\mathrm{c}}\right) \\
\end{array}$ & & & \\
\hline \multirow{11}{*}{ G1-SF } & M01 & 5 & ---- & 49 & 70 & 93.8 & 5.545 & 10.25 & 2386.27 \\
\hline & M02 & 4.5 & ---- & 56 & 72.2 & 88.27 & 5.79 & 17.91 & 2344 \\
\hline & M03 & 6 & ---- & 70.6 & 98.7 & 120.97 & 8.295 & 18 & 2440.2 \\
\hline & M04 & 7 & --- & 64.3 & 77.93 & 94.17 & 8.33 & 19.98 & 2536.44 \\
\hline & M05 & 6.5 & --- & 62.97 & 81.1 & 104.6 & 8.34 & 18.11 & 2466.5 \\
\hline & M06 & 7 & --- & 68.12 & 82.8 & 106.87 & 8.037 & 19.92 & 2381.9 \\
\hline & M07 & 6 & ---- & 100.47 & 113.1 & 131.23 & 9.83 & 21.2 & 2338.19 \\
\hline & M08 & 6 & --- & 111.23 & 124.13 & 149.12 & 10.13 & 24.06 & 2318 \\
\hline & M09 & ---- & 70 & 37 & 64.8 & 73.1 & 6.7 & 13.33 & 2364.43 \\
\hline & M10 & --- & 55 & 19.67 & 34 & 52.2 & 8.5 & 9.98 & 2174.92 \\
\hline & M11 & ---- & 40 & 22 & 38.6 & 58.43 & 8.43 & 10.22 & 2186.58 \\
\hline \multirow{4}{*}{$\begin{array}{l}\text { G2- } \\
\text { FA }\end{array}$} & M12 & 12.5 & --- & 22.6 & 41.56 & 66.3 & 5.68 & 9.36 & 2419.14 \\
\hline & M13 & 8 & ---- & 46.43 & 72.93 & 92.37 & 6.51 & 19.27 & 2460.6 \\
\hline & M14 & 9.5 & --- & 57.34 & 82.7 & 93.33 & 5.8 & 18.99 & 2314.87 \\
\hline & M15 & 11 & ---- & 52.3 & 82.73 & 90.55 & 6.88 & 21.1 & 2434.4 \\
\hline
\end{tabular}

\section{A. Effect of the silica fume content}

The used silica fume content is $20,25,30$, and $35 \%$, respectively. The effect of this parameter could be observed by studying the fresh and hardened properties of mixes M01, M03, M05, and M06. The compressive strength for mixes with different silica fume content at 7,14 , and 28 days' age are shown in Fig. 2.

Findings reveal that at increasing the silica fume content from $20 \%$ to $25 \%$ of binder, enhanced the compressive strength of R.P.C concrete, where 44, 41, and $29 \%$ improving in compressive strength is regarded at age 7, 14, and 28 days, respectively.

However, increasing the silica fume content from $25 \%$ to $30 \%$ and $35 \%$ of binder slightly decreases the compressive strength. The experimental results of the different content of $\mathrm{SF}$, indicates the optimum content of $\mathrm{SF}$ is about $25 \%$ as shown in Fig. 2.

The value of splitting tensile strength $\left(\mathrm{f}_{\mathrm{sp}}\right)$ increases with the increase of SF content. The increasing of silica fume content from $20 \%$ to $25 \%$ lead to significant increase of splitting tensile strength by $49.5 \%$. On the other hand, the splitting tensile strength results of mix containing 30 , and $35 \% \mathrm{SF}$ is very close comparing to mix with $25 \% \mathrm{SF}$, which were very slightly enhanced about $0.5 \%$ only as shown in Fig. 3.

Flexural strength $\left(f_{r}\right)$ results are shown in table VII and illustrated in Fig.3. It shows that the flexural strength of concrete mix also increases with increase in SF content. The flexural strength for mixes with 25,30 , and $35 \%$ SF gain of 75.6, 76.6, and $94.3 \%$ was obtained respectively in comparison with mix had $20 \% \mathrm{SF}$. The maximum value of flexural strength was obtained for $35 \% \mathrm{SF}$ as a replacement with cement quantity.

The flow time of RPC mixes containing $950 \mathrm{~kg} / \mathrm{m} 3$ cementitious content, $2 \%$ superplasticizer, W/C of 0.25 and different partial replacement of cement contents by SF are presented in Table VII. Fig.4 show that increasing silica fume content of binder lead to increases the flow time. It is shown that the optimal content of silica fume is $20 \%$ of binder with $2 \%$ steel fiber get flow time equal 5 sec. It's noticed that were increasing of silica content in RPC lead to 
slightly decreases the slump flow, and gives slightly negative effect on workability. To overcome this negative effect, we may need to increase the proportion of superplasticizer in the mix.
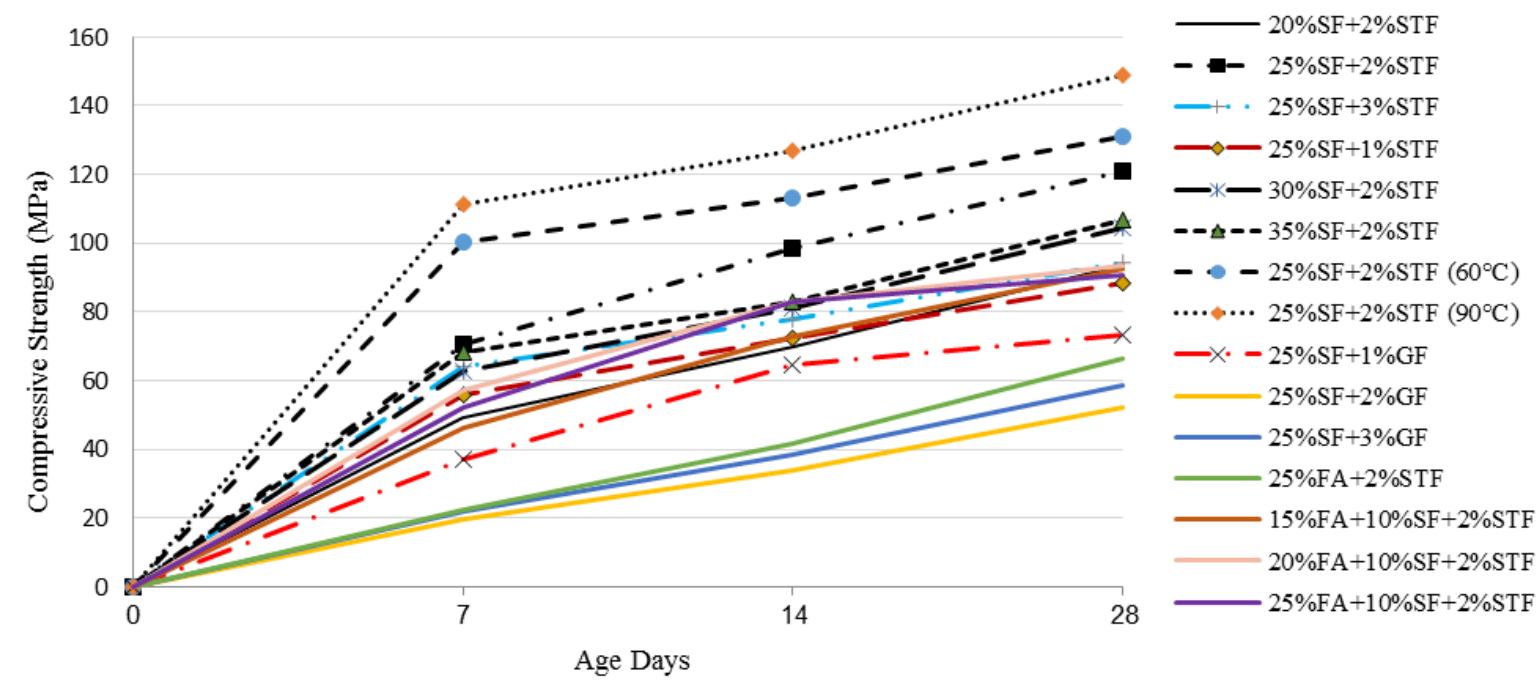

Fig. 1. The compressive strength of RPC mixes at different ages

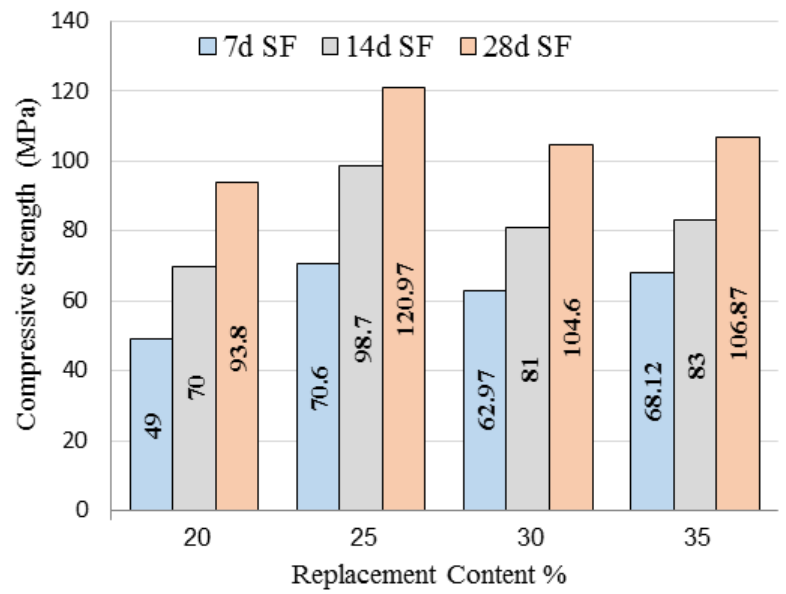

Fig. 2. Effect of silica fume content on the RPC compressive strength at different ages

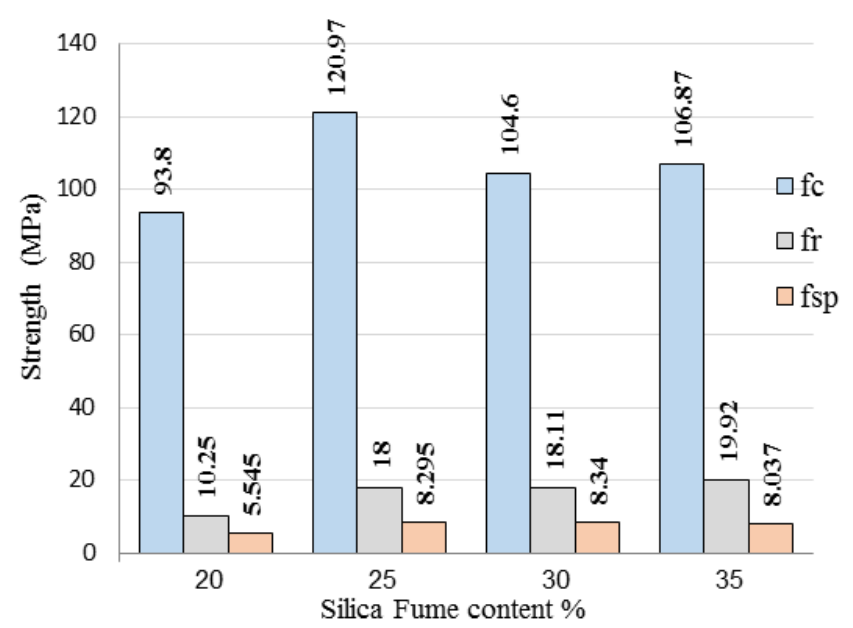

Fig. 3. Effect of silica fume content on the different strength of RPC

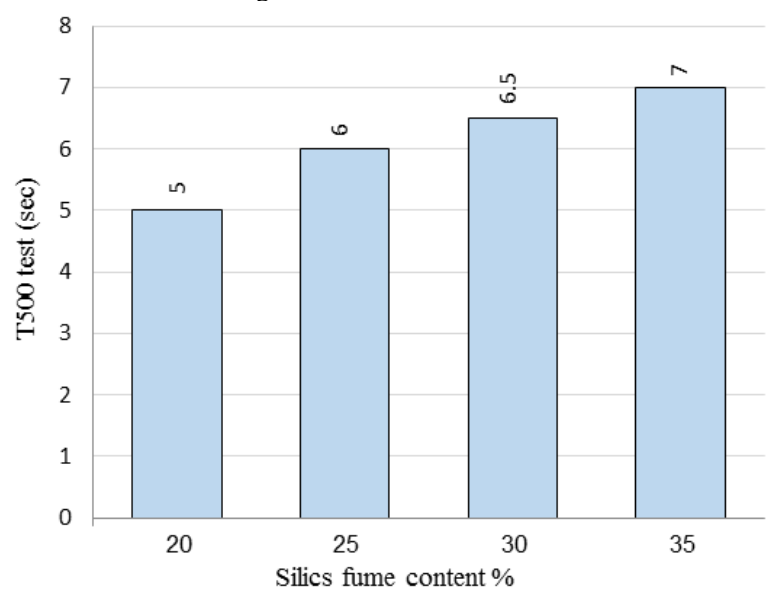

Fig. 4. Effect of silica fume content on the consistency

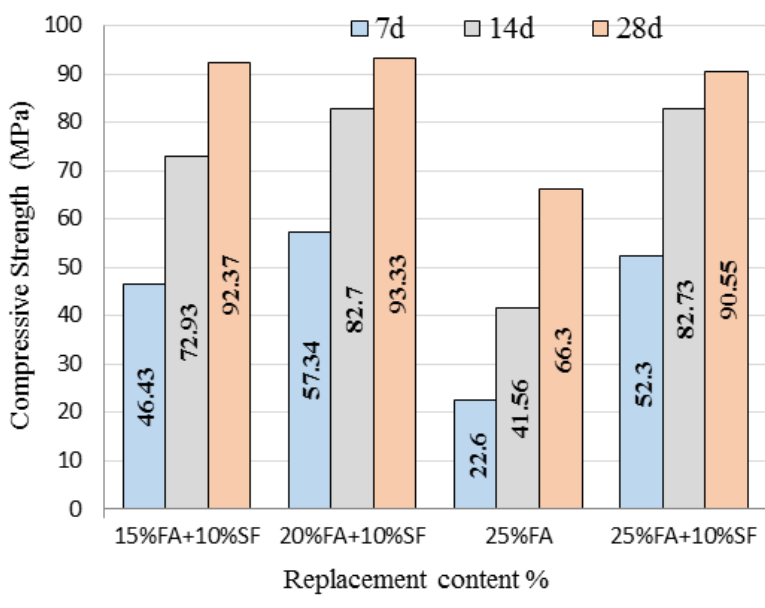

Fig. 5. Effect of fly ash content on the RPC compressive strength at different ages

\section{B. Effect of fly ash content}

The effect of this parameter could be observed by studying the fresh and hardened properties of mixes M13, M14, and M15, which correspond to three different fly ash contents as a replacement of cement; (15 or 20 or $25 \%$ ) FA, also all these mixes containing on constant content of silica fume which were $10 \% \mathrm{SF}$. Also, mix M12 was containing of $25 \%$ FA without SF. 
Fig. 5 demonstrate the effect of changing the fly ash content from $15 \%$ to $20 \%$ and $25 \%$ combination with constant of $10 \% \mathrm{SF}$ which were almost ineffective on the compressive strength of concrete at 28 days age. Replaced of silica fume by fly ash in RPC is economically but give the negative effect on compressive strength. In this study using $25 \% \mathrm{FA}$ of binder without silica fume resulted to compressive strength after 28 days $66.33 \mathrm{MPa}$, which were lower than the mix with combination of replacement materials $10 \% \mathrm{SF}+15 \mathrm{FA}$ by about $29 \%$.

It can be observed that from Fig. 6, increasing the fly ash content from $25 \%$ to $20 \%$ and $15 \%$ with $10 \%$ SF caused to slightly increases the flexural strength of concrete by 1.4 , and $11 \%$, respectively. Also, it's noticed that flexural strength decrease to $9.36 \mathrm{MPa}$ as result to the replacing silica fume by fly ash.

Fig. 6 shows that the increasing of fly ash content from $15 \%$ to $20 \%$ and $25 \%$ with constant $10 \%$ SF effectively increases the splitting tensile strength of RPC by 12.2, and $18.6 \%$, respectively. It is noticed that splitting tensile strength for mix with fully replacing silica fume by fly ash (25\%FA) $5.68 \mathrm{MPa}$, nearly the same result of the content $(15 \% \mathrm{FA}+10 \% \mathrm{SF})$. Then, the best mix with fly ash is $(25 \% \mathrm{FA}+10 \% \mathrm{SF})$ get splitting tensile strength after 28 days $6.88 \mathrm{MPa}$.

The flow time of RPC mixes containing different content of fly ash are presented in Fig. 7 show that increasing fly ash content in the mixture lead to increases the flow time, the

reason for this can be explained as a result to increasing the soft materials in the mix resulting more cohesion, because this materials lead to increase the mixes specific surface area. It is shown that the optimal content of fly ash is $15 \%$ of binder with $10 \%$ silica fume get flow time equal 8 sec. It can be seen that combination SF+FA offered a much better consistency than did FA only. It can be observed that from Fig. 7 fully replacing of the fly silica fume by fly ash produce significant increases in the flow time and decreases the slump flow. This may be caused due to vary specific surface area for fly ash compared to silica fume.

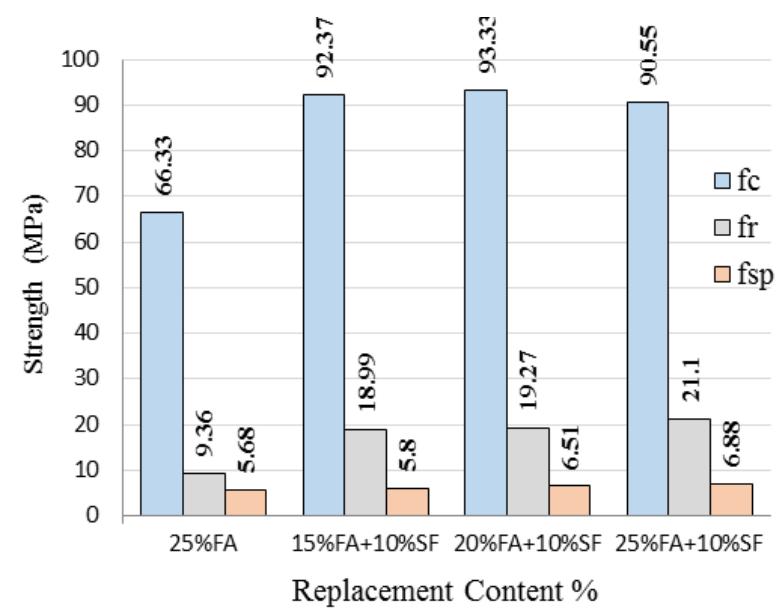

Fig. 6. Effect of fly ash content on the different strength of RPC

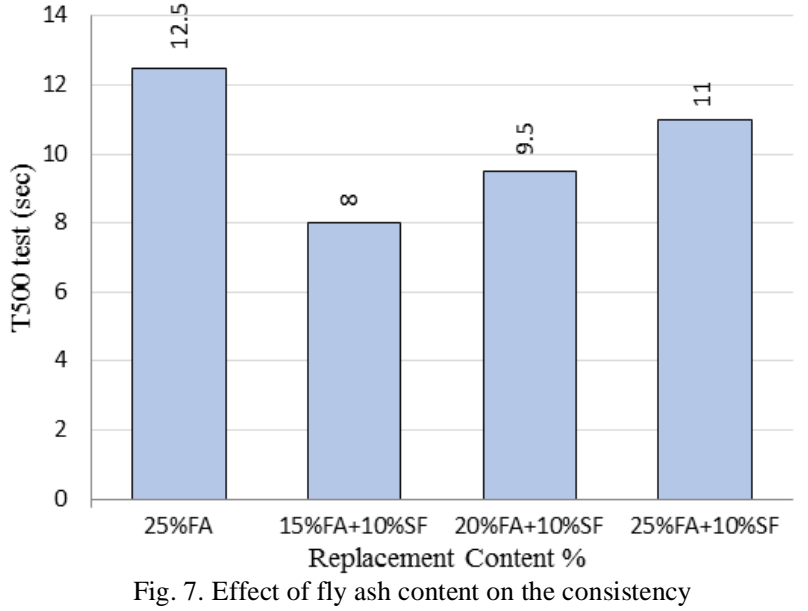

\section{Effect of using different cement replacement combinations}

The effect of this parameter could be observed by studying the behavior of three mixes groups (M03 \& M12 \& M13), (M05 \& M14), and (M06 \& M15), which correspond to three different combinations of replacement contents 25 , 30 , and $35 \%$, respectively, all these mixes Containing $2 \%$ steel fiber.

The first group was Consists of three mixes had 25\% cement replacement content with different mixing from SF and FA, which were $\mathrm{M} 03(0 \% \mathrm{FA}+25 \% \mathrm{SF})$, $\mathrm{M} 12(25 \% \mathrm{FA}+0 \% \mathrm{SF})$, and $\mathrm{M} 13(15 \% \mathrm{FA}+10 \% \mathrm{SF})$. The experimental results of this replacement combinations, indicates the optimum mixing is $0 \% \mathrm{FA}+25 \% \mathrm{SF}$ as shown in Figs. $8 \mathrm{a}-8 \mathrm{~b}$ which show the best result of compressive strength of RPC in different ages, also this combination gain maximum value of splitting tensile strength. The maximum value of flexural strength was obtained from $(15 \% \mathrm{FA}+10 \% \mathrm{SF})$ as a replacement combination, which were nearly the same result of the combination $(0 \% \mathrm{FA}+25 \% \mathrm{SF})$. Also, $(0 \% \mathrm{FA}+25 \% \mathrm{SF})$ in this combination group (25\% replacement content) can be considered as the optimal content for minimum flow time and maximum workability as shown in Fig.8c.

The second group was Consists of two mixes had $30 \%$ cement replacement content with different combinations, which were M05(0\%FA+30\%SF), M14(20\%FA+10\%SF). The results of this mixes, indicates the optimum mixing is $0 \% \mathrm{FA}+30 \% \mathrm{SF}$ as shown in Figs. $8 \mathrm{a}-8 \mathrm{~b}$, which show that this mix gain maximum compressive strength and maximum splitting tensile strength. However, the maximum value of flexural strength was obtained from $(20 \% \mathrm{FA}+10 \% \mathrm{SF})$, while it was close to the value from combination $(0 \% \mathrm{FA}+30 \% \mathrm{SF})$. It can be observed that from Fig. $8 \mathrm{c}$, partially replacing of the fly silica fume by fly ash $(20 \% \mathrm{FA}+10 \% \mathrm{SF})$ produce significant increase in the flow time and decreases the slump flow. This may be caused due to the large specific surface area for fly ash compared to silica fume. The third group was Consists of two mixes had $35 \%$ cement replacement content with different combinations, which were M06(0\%FA+35\%SF), $\mathrm{M} 15(25 \% \mathrm{FA}+10 \% \mathrm{SF})$. The results of this combinations, indicates the optimum mixing is $(0 \% \mathrm{FA}+30 \% \mathrm{SF})$ as shown in Figs. 8a-8b, which show that this mix gain maximum compressive strength at different ages and had maximum 
splitting tensile strength. However, the maximum value of flexural strength was obtained from $(25 \% \mathrm{FA}+10 \% \mathrm{SF})$, which were near the flexural strength from combination $(0 \% \mathrm{FA}+35 \% \mathrm{SF})$. It can be observed that from Fig. $8 \mathrm{c}$, partially replacing of the fly silica fume by fly ash $(25 \% \mathrm{FA}+10 \% \mathrm{SF})$ produce significant increase in the flow time and consistency, may be because of the silica fume specific surface area is differ to specific surface area of fly ash.
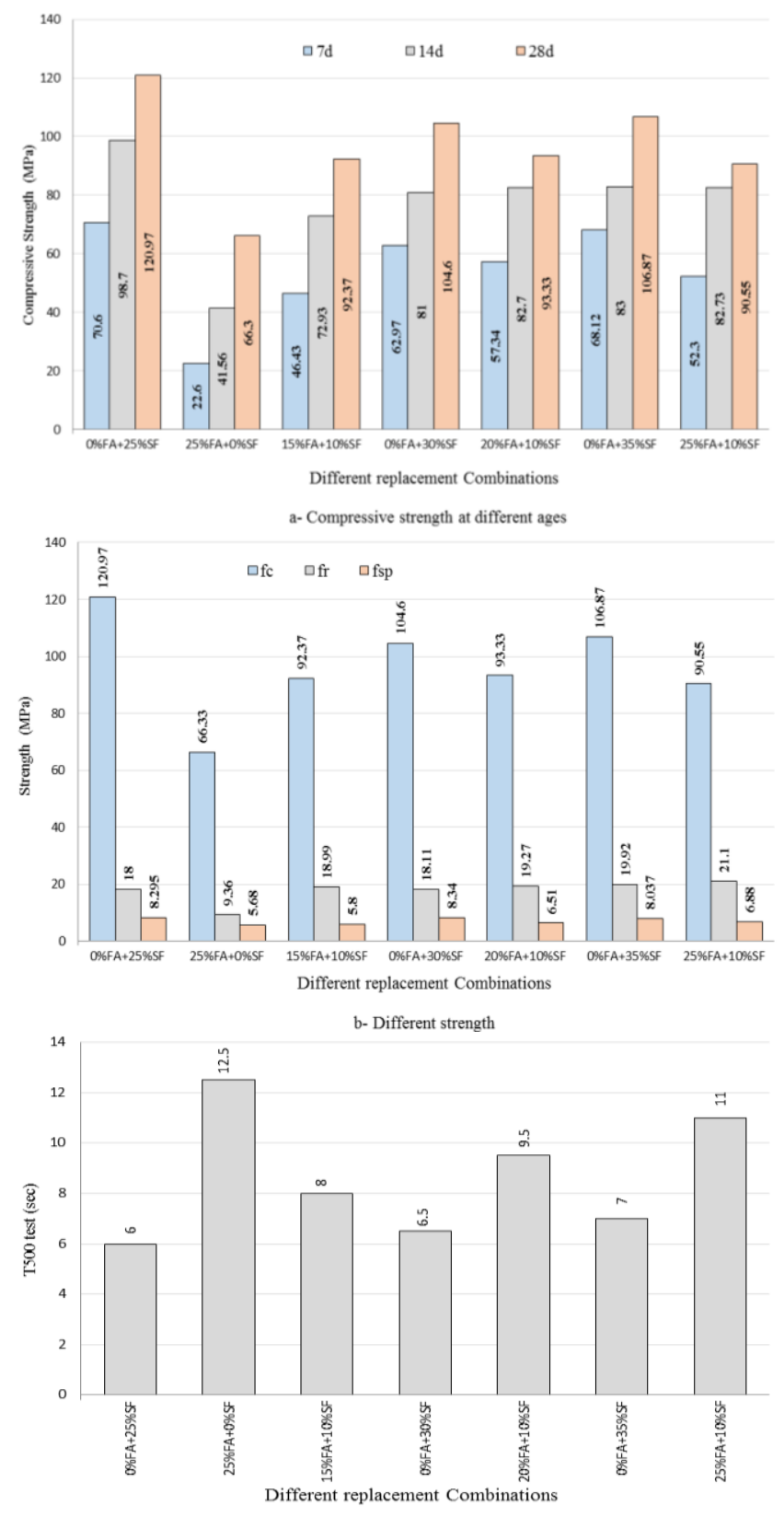

c- Flow time

Fig. 8. Effect of using different cement replacement combinations on the RPC properties

\section{Effect of steel fiber percentage}

The used steel fiber percentage is 1,2 , and $3 \%$. The effect of this parameter could be observed by studying the fresh and hardened properties of mixes M02, M03, and M04, respectively. Fig. 9 shows that the effect of steel fiber on the compressive strength (fc) at 28-day age at different content level. It can be observed that from Fig. 9 the increasing of steel fiber content from $1 \%$ to $2 \%$ increased the compressive strength about $37 \%$. However, increasing the steel fiber content from $2 \%$ to $3 \%$ (by total volume) decreases the compressive strength; it is shown that the optimal value of steel fiber is $2 \%$. The average flexural strength (fr) of RPC with $2 \%$ and $3 \%$ steel fibers increase about 1 and $11 \%$ respectively, compared to mix with $1 \%$ steel fiber. The increasing of steel fiber percentage from $1 \%$ to $2 \%$ caused to significant increase of splitting tensile strength by $42.7 \%$. On the other hand, the splitting tensile strength results of mix containing $3 \%$ steel fiber comparing to mix with $2 \%$ steel fiber were very slightly enhanced about $0.42 \%$. Fig. 10 demonstrates the effect of increasing the Steel fiber content by total volume of RPC on the consistency; it is clear that increasing steel fiber percentage's increases the flow time. This is due to the increased density and cohesion of the mixture. The density of RPC increased when the steel fiber content increases from $1 \%$ to $2 \%$ and $3 \%$ by $4.1 \%$ and $8.2 \%$ respectively.

\section{E. Effect of glass fiber percentage}

The effect of this parameter could be observed by studying the fresh and hardened properties of mixes M09, M10, and M11, which correspond to three different glass fiber percentages; 1, 2, 3\% GF, also all these mixes containing on constant content of silica fume which were $25 \%$ SF. Fig. 11 shows that the effect of glass fiber on the 28-day compressive strength at different content level. It can be observed that from Fig. 11 the increasing of glass fiber content from $1 \%$ to $2 \%$ and $3 \%$ lead to decreasing the compressive strength of concrete, the optimal value of glass fiber $1 \%$ where get compressive strength after 28-days 73.1 $\mathrm{MPa}$. Also, it can be observed that from Fig. 11 increasing the glass fiber content from $1 \%$ to $2 \%$ and $3 \%$ effectively decreasing the flexural strength of concrete by 25.1 and $23.3 \%$, respectively. It is shown that the optimal value of glass fiber $1 \%$, which were give flexural strength after 28 days 13.33 MPa. Increasing of the glass fiber content from $1 \%$ to $2 \%$ effectively increasing the splitting tensile strength of concrete by $26.8 \%$ but increasing of the glass fiber content from $2 \%$ to $3 \%$ is approximately not effect on splitting tensile strength. Fig.12 shows were increasing of the glass fiber content in RPC lead up to decreases the slump flow, and gives negative effect on workability.

\section{$F$. Effect of fiber material type}

Generally, using steel fibers produce compressive and flexural strengths higher than glass fiber at different content level as shown in Figs. 13-14. This may be due to weak cohesion of glass fiber with the mixture, which has led to less resistance compared to steel fibers. However, the glass fiber was give the splitting tensile strength higher than steel fiber but very little by about average $6 \%$.

\section{G. Statically analysis}

In this study, results showed that the increase of compressive strength is significant at early age in compared with later ages. The early age strength raises could be because of finer particle size of SF and FA, which accelerate the hydration reaction and packs into cement particles gaps.

Table VII and Fig. 1 show the results of compressive strength at different ages. The analysis of these results yields the following equations, as shown in Fig. 15.

$$
\mathrm{f}_{\mathrm{c} 7}=0.565 \mathrm{f}_{\mathrm{c} 28}, \mathrm{f}_{\mathrm{c} 14}=0.792 \mathrm{f}_{\mathrm{c} 28}
$$


When comparing of flexural strength and splitting tensile strength result of all mixes to compressive strength result, it's noticed that, flexural strength and splitting strength result represent about $8.48 \%$ and $17.94 \%$ nearly of compressive strength result of the same mixes as shown in Fig. 16.

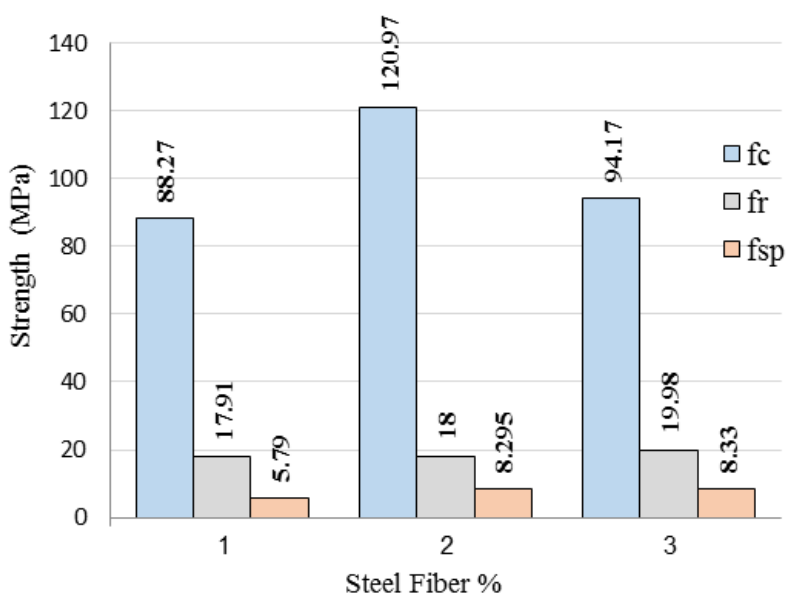

Fig. 9. Effect of steel fiber percentage on the different strength of RPC

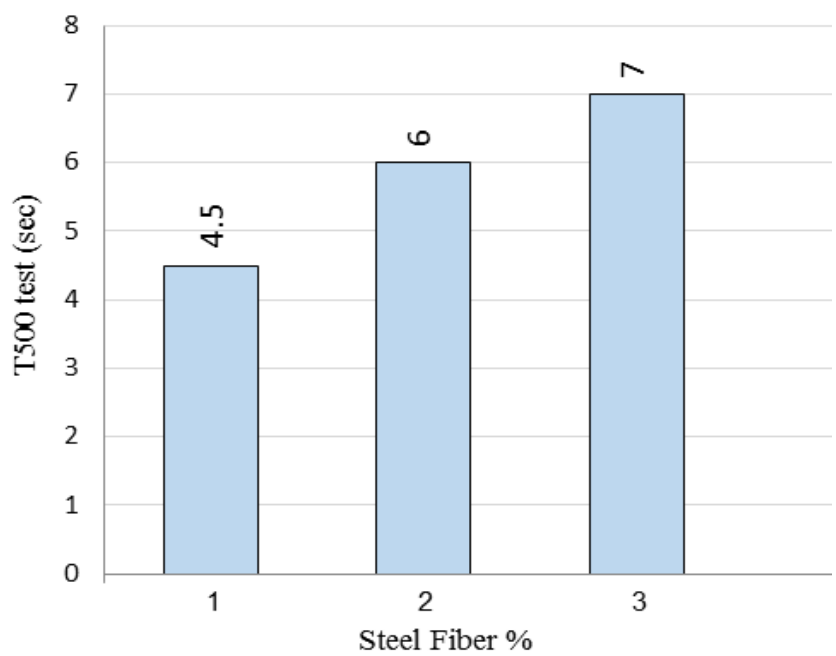

Fig. 10. Effect of steel fiber percentage on the RPC consistency

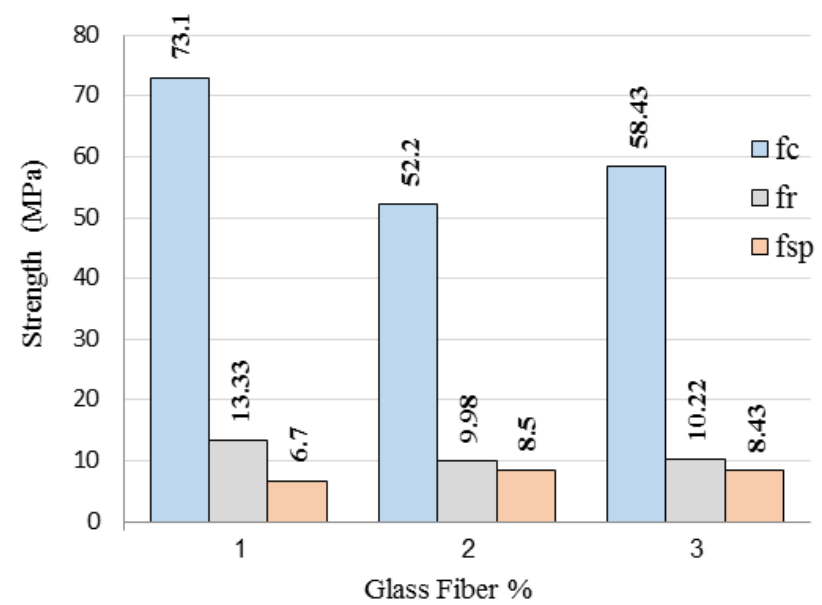

Fig. 11. Effect of glass fiber percentage on the different strength of RPC

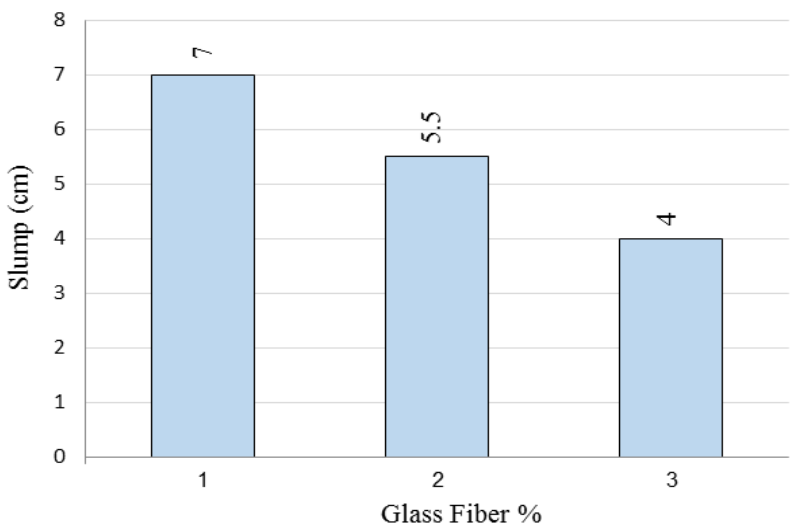

Fig. 12. Effect of glass fiber percentage on the RPC consistency

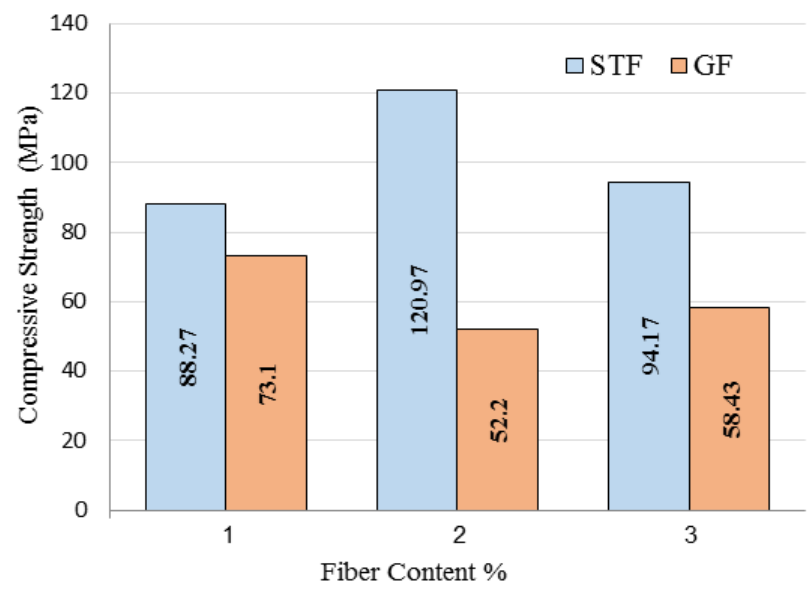

Fig. 13. Effect of fiber type on the RPC compressive strength (28-day) at different content percentages

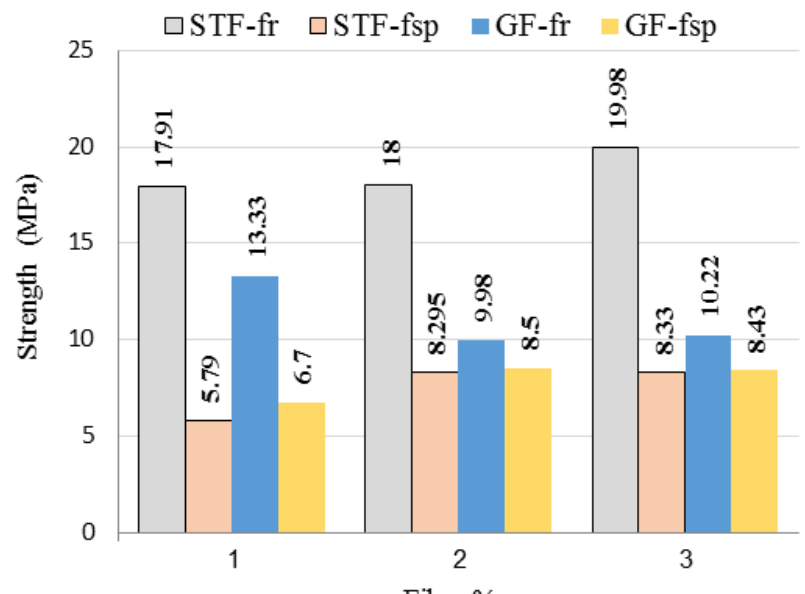

Fig. 14. Effect of fiber type on the different strength at various content percentages 


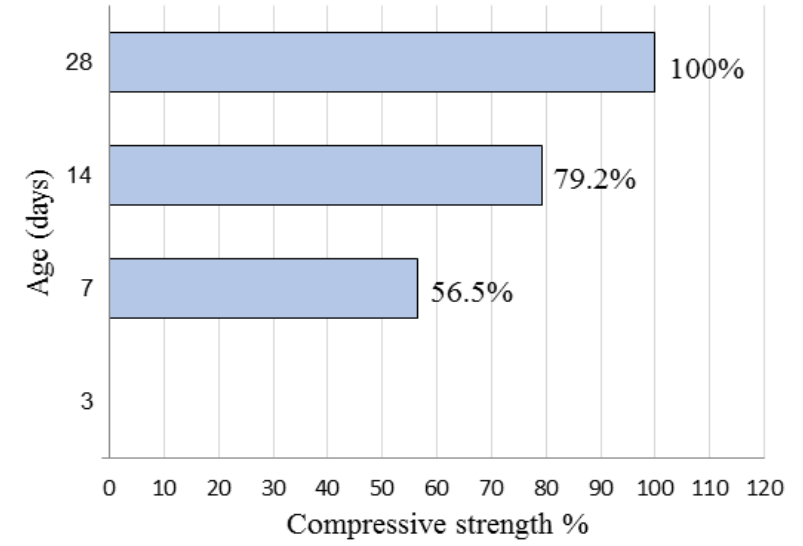

Fig. 15. Relative gain of compressive strength of RPC at different ages

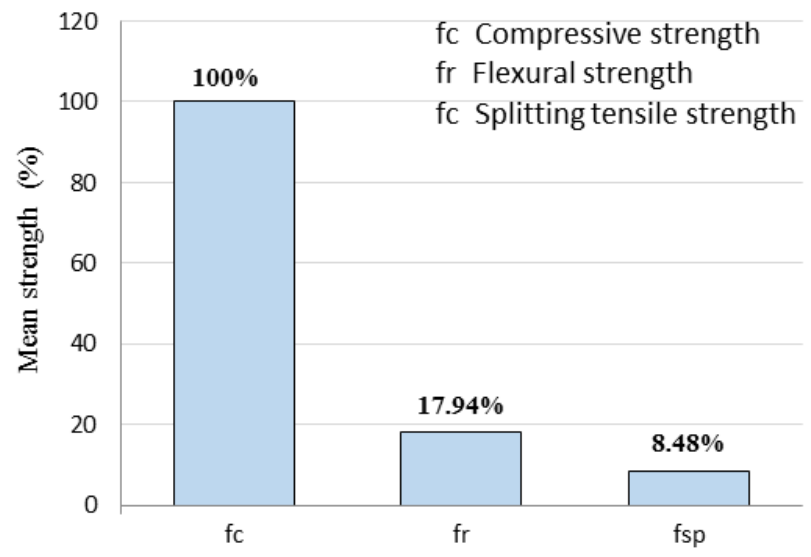

Fig. 16. Compressive strength of RPC in comparison to other strength

\section{H. Effect of the curing condition}

The effect of this parameter could be observed by studying the mechanical properties of mixes M03, M07, and M08, which correspond to three different curing conditions; were normal water curing at $25^{\circ} \mathrm{C}$, hot water curing at $60^{\circ} \mathrm{C}$, and $90^{\circ} \mathrm{C}$ for 1-day, respectively, also all these mixes containing on constant content of silica fume which were $25 \% \mathrm{SF}$.

It can be observed that from Fig. 17 the temperature of curing has significant effect on compressive strength of tested specimens at different ages. The highest effect at age 7 days, where the compressive strength 7 days increased by $42.3 \%$, and $57.5 \%$ when the temperature of curing water was increased from ambient temperature to $60^{\circ} \mathrm{C}, 90^{\circ} \mathrm{C}$ respectively. At age 14 days, the corresponding percentages increasing where $14.4 \%, 28.6 \%$ when the temperature of curing water was increased from ambient temperature to $60^{\circ} \mathrm{C} \& 90^{\circ} \mathrm{C}$ respectively. Also, at age 28 days, the corresponding percentages increasing where $8 \%$, and $23 \%$ when the temperature of curing water was increased from ambient temperature to $60^{\circ} \mathrm{C} \& 90^{\circ} \mathrm{C}$, respectively.

Fig. 18 demonstrates the effect of increasing temperature of curing water; it is clear that increasing the temperature of curing water increases the splitting tensile strength of RPC by $18.5 \%, 22.2 \%$, when the temperature of curing water was increased from ambient temperature to $60^{\circ} \mathrm{C}$, and $90^{\circ} \mathrm{C}$ respectively.

The flexural strength results are shown in Fig.18. It shows that the flexural strength of concrete mix also increases with increase in temperature of curing water. The flexural strength for mixes which curing in hot water $60^{\circ} \mathrm{C}$, and $90^{\circ} \mathrm{C}$ for one day which were increases by $17.7 \%$, and $33.7 \%$, respectively in comparison with mix curing in normal water $25^{\circ} \mathrm{C}$.

It can be observed that from Fig. 19 the density of RPC decreased when the temperature of curing water was increased from ambient temperature $\left(25^{\circ} \mathrm{C}\right)$ to $60^{\circ} \mathrm{C}$ and $90^{\circ} \mathrm{C}$ by $4.2 \%$, and $5 \%$ respectively.

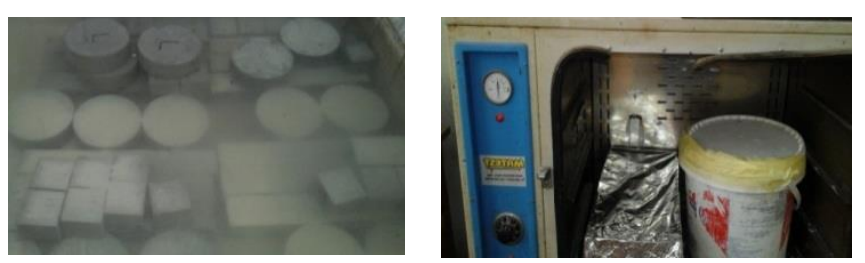

Specimens in normal water curing and hot water curing for 1-day

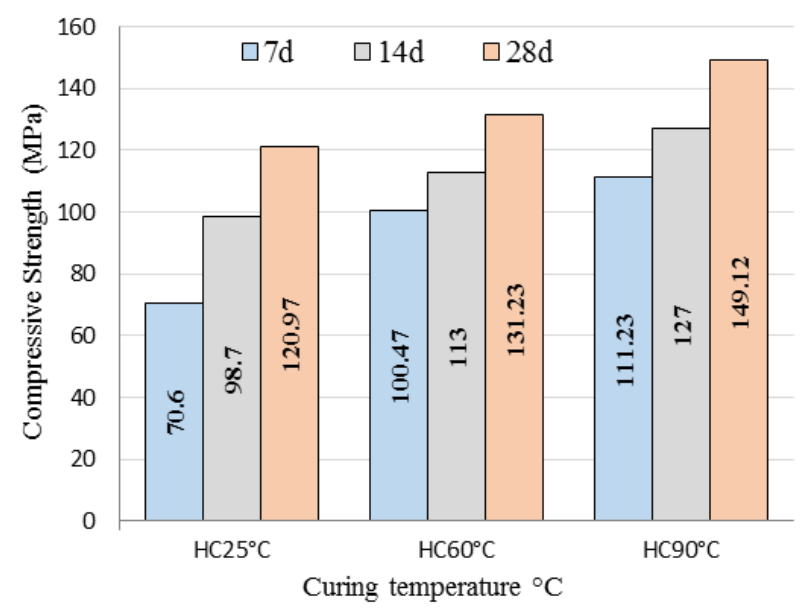

Fig. 17. Effect of curing temperature on the compressive strength of RPC at different ages

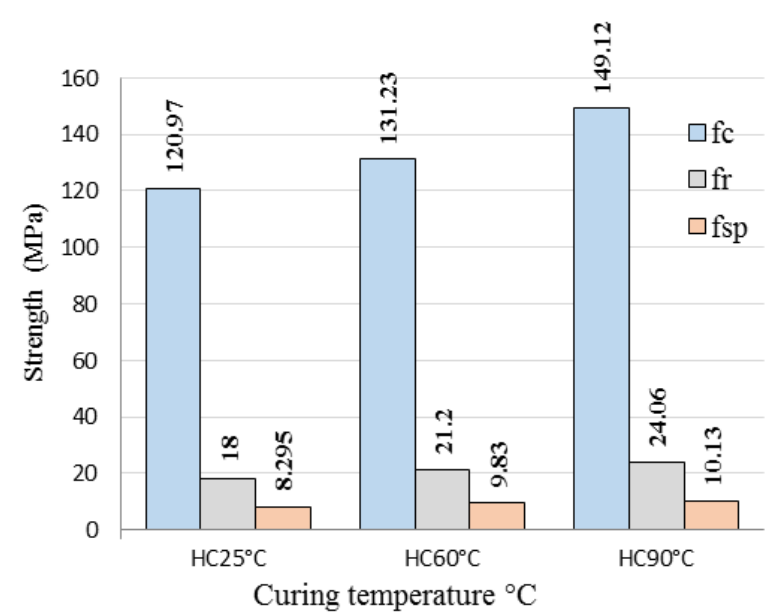

Fig. 18. Effect of curing temperature on the different strength of RPC 


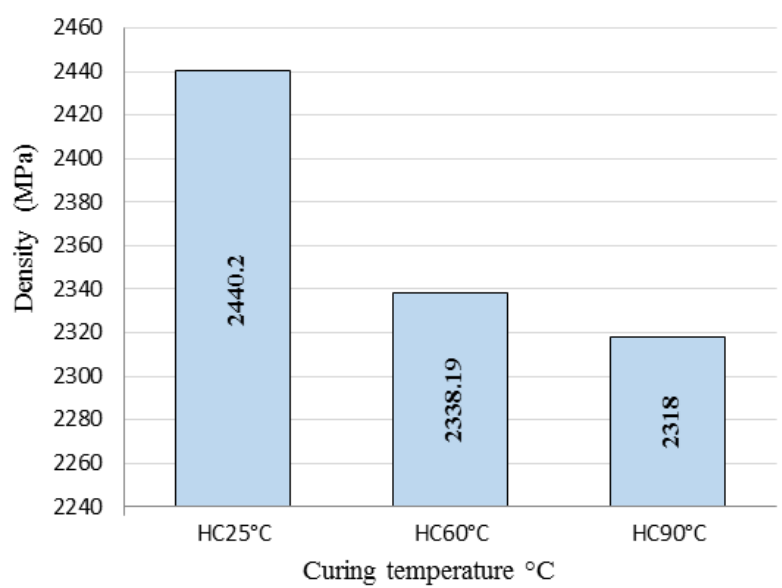

Fig. 19. Effect of curing temperature on the density of RPC

\section{CONCLUSIONS}

The following conclusions can be stated on the basis of the above discussion.

1- When the SF, and FA content increases, the flow ability of RPC decreases, as the increase of soft materials in the mix leads to increased density of the mixture. The optimal content of silica fume is $20 \%$ of binder with $2 \%$ steel fiber which were get flow time equal 5 sec.

2- With low quality superplasticizer it was difficult to achieve the required workability at low waterbinder ratio, so the workability can further be improved by choosing advanced generation superplasticizers and thus reducing the water/binder ratio, and also workability can further be improved by increasing the superplasticizers percentage in the mixture.

3- The results showed that the optimum replacement percentage for maximum compressive strength was $25 \%$ for concrete incorporating $\mathrm{SF}$ or $(\mathrm{SF}+\mathrm{FA})$, when curing under normal condition $25^{\circ} \mathrm{C}$.

4- The maximum compressive strength achieved was about $149.1 \mathrm{Mpa}$ at hot water curing 90 'C for 1-day.

5- The average value of flexural strength is about $17.94 \%$ of the 28-days compressive strength of the same mixes. The maximum value of flexural strength was obtained for $25 \% \mathrm{FA}+10 \% \mathrm{SF}$ as a replacement of cement.

6- The test results indicate that the optimum replacement percentage for maximum hardened properties was $25 \%$ for concrete incorporating SF or (SF+FA) including $2 \%$ steel fiber. While, based on the results, it can be observed that concrete prepared with FA only replacement material indicated reduced strengths compared to mixes containing SF or (SF+FA).

\section{REFERENCES}

[1] Washer, G., Fuchs, P., Graybeal, B.A. and Hartmann, J.L., "Ultrasonic Testing of Reactive Powder Concrete, IEEE Transactions on ultrasonic ferroelectrics and frequency control, 2004, Vol. 51, No. 2, pp. 193-201

[2] Lee, N.P. and Chisholm, D.H., "Study Report Reactive Powder Concrete", BRANZ, 2005, Vol. 146, pp. 1-29.

[3] Shaheen, E. and Shrive, N.G., "Optimization of Mechanical Properties and Durability of Reactive Powder Concrete", ACI Materials Journal, 2006, Vol. 103, No. 6, pp. 444-451.

[4] Lee MG, Wang YC, Chiu CT, A preliminary study of reactive powder concrete as a new repair material. Construction Build Mater, 2007, 21(1):182-189.

[5] Sarika S and Elson john,A, Study of Reactive Powder Concrete International Journal of Engineering Research \& Technology (IJERT) Issn:2278-0181.Vol.4 Issue, 2015.

[6] Yin-Wen Chan and Shu-Hsien Chu (2003), "Effect of silica fume on steel fiber bond characteristics in reactive powder concrete," Cement and Concrete Research, No- 34, pp. 1167-1172, 2004.

[7] Shaheen E, Shrive NG, Optimization of mechanical properties and durability of reactive powder concrete, ACI Mater J 103(6):444-451, 2006.

[8] Sadrekarimi A, Development of a lightweight reactive powder concrete. J Adv. Concrete Techno 2(3):409-417, 2004.

[9] Zhang Yunsheng, Sun Wei, Liu Sifeng, Jiao Chujie, and Lai Jianzhong, "Preparation of C200 green reactive powder concrete and its static-dynamic behaviors," Cement \& Concrete Composites, Vol.30, pp. 831-838, 2008

[10] H. M Al -Hassani, W. I Khalil, L. S Danha, "Mechanical properties of Reactive powder concrete with various steel fibres and silicafume contents", Acta Technica Corviniensis, pp.47-58, 2014.

[11] Osama Elouh and Mamoun Alqedra. Properties of Locally Produced Reactive Powder Concrete. International Journal of Advanced Structures and Geotechnical Engineering, 2014

[12] Mohammed Mansour, Kadhum Alkafaji, "Performance of Ractive powder concrete slabs with different curing conditions", Journal of Engineering and Technology Research, Vol.6(6), pp.81-93, 2014.

[13] Sirisala Chandrusha, G. Mahaboob Basha, Shaik Rehana Begum andT. Yaswanth kumar." Behavior of Concrete by using Waste Glass Powder and Fly Ash as a Partial Replacement of Cement". International Journal of Engineering Science and Computing, November 2017.

[14] Griffiths R.., An assessment of the properties and degradation behavior of glass-fiber-reinforced polyester polymer concrete. Composites Science and Technology, 2000, pp. 2747-2753. 